\title{
Canine lymphoma: Pathological and clinical characteristics of patients treated at a referral hospital
}

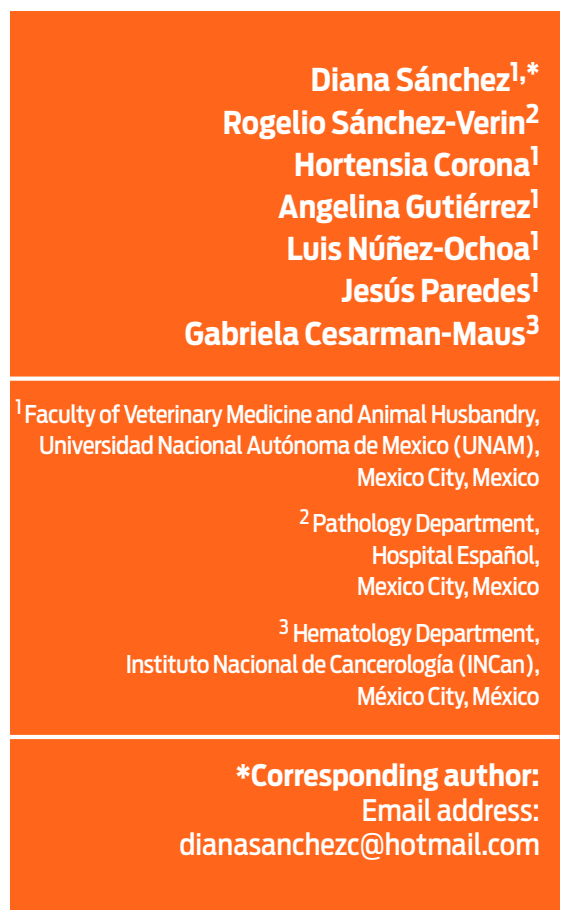

Accepted: 2019-06-03 Published: $2019-06-28$ Additional information and declarations can be found on page 9

@) Copyright 2019 Diana Sánchez et al.

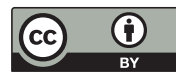

Distributed under Creative Commons CC-BY 4.0

\section{Abstract}

Non-Hodgkin's lymphomas are common canine cancers with variable demographic and clinical presentations. Their pathological characterization and treatment lag far behind those of humans. We describe consecutive lymphoma patients detected over a one-year period at the National Autonomous University of Mexico (UNAM). Of 4,512 dogs: 220 (4.9\%) had a cancer diagnosis, of which 27 (0.6\%) had lymphoma (12\% of cancer patients). We found an association with Miniature Schnauzers, which represented 18.5\% $(5 / 27)$ of lymphoma patients, but it was only $6.4 \%(288 / 4,512)$ of the dogs studied in this time period $(p<0.011)$. Miniature Schnauzers and mongrels together constituted nearly half of lymphoma cases. Mean age at diagnosis was 7.5 years (3-14), with a female to male ratio of $1.7: 1$. We found no correlation between lymphoma and castration status. Most patients presented nodal involvement (80\%), were in advanced stages III/IV (90\%) and had B-cell versus T-cell tumors (64\%/36\%). Only two histopathological patterns were seen, both with diffuse nodal-replacement by large immunoblast and/ or centroblast-like cells; one having numerous tingible-body macrophages which are suggestive of a high proliferative rate. Chemotherapy was given to 15 patients (65\%) with an overall response of 73\% (3 complete responses/8 partial responses) and a mean overall survival of 219 days (4-586; $\mathrm{SD} \pm 185)$. One cutaneous lymphoma-patient achieved partial response (PR) with lomustine/prednisone, and treatment was still ongoing at 548 days. Earlier diagnosis, better lymphoma subtype distinction, and specific curative treatments are needed.

Keywords: Dog, Canine, Cancer, Lymphoma

\section{Cite this as:}

Sánchez D, Sánchez-Verin R, Corona H, Gutiérrez A, Núñez-Ochoa L, Paredes J, Cesarman-Maus G. Canine lymphoma: Pathological and clinical characteristics of patients treated at a referral hospital. Veterinaria México OA. 2019;(2). doi: 10.22201/ fmvz.24486760e.2019.2.495. 


\section{Introduction}

Lymphomas are a group of diverse monoclonal neoplasms that originate from $\mathrm{B}, \mathrm{T}$, or natural killer (NK) lymphocytes at different stages of maturation. ${ }^{1,2}$ As a group, lymphomas represent one of the most common tumors in dogs, comprising between $7-24 \%$ of all tumors and $83-90 \%$ of hematological cancers. ${ }^{3}$ There is no information on its annual incidence in Mexico. In the United States, between 13 to 24 cases per 100,000 dogs ${ }^{4}$ are estimated to be lymphomas. Middle aged and old dogs are mostly affected. ${ }^{1,2}$ Interestingly, there are certain breeds with higher incidence of lymphoma such as Boxers, Bullmastiffs, and Bulldogs. ${ }^{5}$ Clinically, primary nodal involvement by lymphoma is more common than extra-nodal disease, but any organ may be affected. ${ }^{6}$ In terms of cell of origin, B-cell-derived tumors are more prevalent than those derived from T-cells (ratio of 2:1). ${ }^{7}$ Since the decade of 1980, the introduction of multidrug chemotherapy regimens for the treatment of canine lymphoma has made the disease treatable, but still rarely curable. ${ }^{1}$ Currently, the standard treatment in veterinary medicine for canine lymphoma is based most commonly on CHOP (cyclophosphamide, hydroxy-daunorubicin, vincristine and prednisone), with or without the addition of L-asparaginase, not considering the cell of origin or type of lymphoma. T-cell lymphoma respond less favorably and generally have a worse prognosis. ${ }^{8,9}$ In humans, different types of B, T or NK-cell lymphomas are treated by tailored chemotherapy protocols, which should ideally be the case for dogs. ${ }^{10}$ We present demographic and clinical information on canine lymphoma in a referral center in Mexico. It provides further insight into our patient population and points areas to improve its diagnosis and clinical management.

\section{Materials and methods Animals}

The Veterinary Specialty Hospital (HVE) at UNAM is a veterinary referral center. Of 4,512 dogs seen over one year (2013), 220 (4.9\%) were diagnosed with cancer, of which $27(0.6 \%)$ had lymphoma. Clinical data, pathology, treatment and outcomes from consecutive lymphoma patients were retrospectively analyzed from medical records. Clinical data from all patients seen at the HVE were available to be reviewed for comparison. The clinical data included breed, sex, neutering status, age at diagnosis, clinical signs, complete blood count (CBC), serum biochemistry profile, diagnostic procedures, and clinical stage according to the World Health Organization (WHO) criteria, as well as treatments, response rates and survival. Response to treatment was evaluated using Response Evaluation Criteria for canine peripheral nodal lymphoma ${ }^{11}$ as follows: complete response (CR) as complete disappearance of all clinically measurable disease; partial response (PR) as $>30 \%$ but $<100 \%$ reduction in the sum of the longest diameter of measurable tumors; stable disease (SD) as $<30 \%$ reduction or $<20 \%$ increase in the sum of the longest diameters of measurable tumors without the appearance of new neoplastic lesions; and progressive disease (PD) as an increase of $>20 \%$ in the sum of the longest diameters of measurable tumors or the appearance of new neoplastic lesions. Overall survival (OS) was defined as the time from the date of diagnosis to the date of death from any cause, and response duration (RD) was defined as the duration from the documented response (CR or PR) to the date of relapse or progression. 


\section{Pathology}

The initial diagnosis of lymphoma was made on fine needle ponction of lymph nodes (27 cases) by the Pathology Department of the Facultad de Medicina Veterinaria y Zootecnia, UNAM. Eleven cases counted with additional tissue biopsies $(11 / 27)$ and were re-reviewed by two human hemato-pathologists at the Hospital Español, on haematoxylin and eosin (HE) stained slides, and then by immunohistochemistry (IHC) for CD3 (T-cell marker, Dako, clone F7.2.38) and CD79a (B-cell marker, Dako, clone JCB117) with monoclonal mouse anti-human antibodies (Dako, Carpinteria CA), using a manual immunoperoxidase method. Briefly, $2 \mu \mathrm{m}$ sections were obtained and blocked for endogenous peroxidase activity with 3\% hydrogen peroxide in ethanol (15 min), then washed in running water (5 min). For antigen retrieval, the slides were pretreated with $10 \mathrm{mM}$ citrate ( $\mathrm{pH}$ 6.0) in a pressure cooker (30 min), followed by a bath in distilled water. All further steps were performed at room temperature in a hydrated chamber: CD3 or CD79a at 1:200 dilutions were incubated (30 min) and detected by Immunodetector DAB (BioSB, Santa Barbara, $C A$ ). For the $\mathrm{IHC}$, samples were considered positive to $C D 3$ or CD79a when an immunoexpression in membrane pattern was found. Amygdaline tissue was used as control.

\section{Treatment}

A total of $85 \%$ (23/27) of lymphoma patients were treated, 65\% (15/23) received a CHOP-based protocol (fourteen received a Madison-Wisconsin-19 weeks protocol without L-asparaginase, and one patient received $\mathrm{CHOP} / \mathrm{L}$-asparaginase) $)^{12}$. Seven (30\%) received prednisone alone, and one with cutaneous lymphoma was treated with lomustine/prednisone. Four dogs were either deemed too sick to undergo chemotherapy or the owners did not accept treatment.

\section{Statistical analysis}

All data were analyzed using the commercially available statistic software GraphPad Prism 6.0 software. Descriptive statistic included measures of central tendency and spread. Survival probabilities were estimated using the Kaplan-Meier product limit method.

\section{Results and discussion}

Among 4,512 dogs seen at the HVE over one year (2,232 females and 2,280 males), 220 (4.9\%) were diagnosed with cancer. Lymphoma, diagnosed in 27 patients, was the third most common cancer after mast cell and mammary gland tumors, representing $12 \%$ of all cancer patients and $0.6 \%$ of all dogs. The mean age at diagnosis was 7.5 years (range: $3-14$ ), with most dogs (81.5\%) being over the age of five, which is consistent with other cohorts. ${ }^{8,13-15}$ Regarding incidence by gender, there was a higher incidence in females (17 dogs) than in males (10 dogs) and we found a slight female predominance (ratio 1.7:1). Other authors have reported a higher incidence in males ${ }^{13,16}$ or no difference at all. $8,14,17,18 \mathrm{~A}$ recent study analyzing the risk of developing lymphoma according to gender in 1,171,915 
Table 1. Main reason for consultation and clinical stage at lymphoma diagnosis in dogs. The table shows the number and percentage of patients by clinical stage at diagnosis and by reason for consultation

\begin{tabular}{|c|c|c|c|c|c|c|c|c|c|c|}
\hline \multirow[b]{2}{*}{ Patients } & \multicolumn{7}{|c|}{ Main reason for consultation } & \multicolumn{3}{|c|}{ Clinical stage } \\
\hline & $\begin{array}{c}\text { Palpable } \\
\text { painless } \\
\text { lymph node } \\
\text { enlargement }\end{array}$ & $\begin{array}{c}\text { Weight } \\
\text { loss }\end{array}$ & $\begin{array}{l}\text { Poor } \\
\text { vision }\end{array}$ & $\begin{array}{l}\text { Pruritus } \\
\text { with hair } \\
\text { loss }\end{array}$ & Ascites & Orchitis & Incidental & I & III & IV \\
\hline Number & 17 & 5 & 1 & 1 & 1 & 1 & 1 & 1 & 7 & 19 \\
\hline Percentage (\%) & 64 & 18.5 & 3.7 & 3.7 & 3.7 & 3.7 & 3.7 & 3.7 & 26 & 70.3 \\
\hline Total & \multicolumn{7}{|c|}{$27(100 \%)$} & \multicolumn{3}{|c|}{27 (100\%) } \\
\hline
\end{tabular}

dogs reported that intact females had a lower risk than males. ${ }^{19}$ We found no association between castration status and the development of lymphoma; there were 6/17 (35\%) neutered females with lymphoma versus 649/2,232 (29\%) without lymphoma $(p=0.77)$, and $0 / 10(0 \%)$ neutered males with lymphoma versus 45/2,280 (2\%) without lymphoma $(p=1)$. The most prevalent breeds of dogs with lymphoma were: mongrels $(7 / 27,26 \%)$ and Miniature Schnauzers (5/27, 18.5\%); while in Beagles, Boxers, Golden Retrievers, Great Danes and Poodles there were two dogs of each, (representing 7.4\% for each breed). There was only one dog of the following breeds: English Bulldog, Rhodesian, Scottish Terrier, Shar-Pei and West Highland White Terrier (3.7\% each). These mostly correspond to breeds without lymphoma seen at the HVE: mongrel (18.5\%), Poodle (15\%), Golden/Labrador (9\%), Cocker Spaniel (7.5\%), Miniature Schnauzer (6.4\%), Chihuahua (5.5\%), Dachshund (4.5\%), German Shepherd (3.5\%), Boxer (3\%), Scottish Terrier (2.5\%) and $24.5 \%$ of other breeds with less than $2 \%$ of individuals. There was a significant association of lymphoma with Miniature Schnauzers, which made up $18.5 \%$ (5/27) of lymphoma patients and only $6.4 \%$ (288/4512) of all dogs $(p<0.011)$. In the Veterinary Medical Database, of 14,573 dogs with lymphoma documented over a 38-year period, the most frequently affected breeds were mongrels (22\%), Golden Retrievers (10\%), Labrador Retrievers (6\%), German Shepherds (5\%) and Boxers (5\%). ${ }^{19}$ Other reports confirm the predisposition in Boxers, $8,15,18,20,21$ as well as in Colden Retrievers, $3,20,22$ and mongrels. ${ }^{16,20}$

It took owners a mean of 50 days (1-66 days) to take their dogs to a veterinarian, after having detected an abnormality. The main reason for consultation was palpable painless lymph node enlargement in 64\% (17/27). In the remaining patients, the reasons were varied, including weight loss, poor vision, pruritus with hair loss in the patient with cutaneous lymphoma, peritoneal effusion, and orchitis. In one dog, lymphoma was an incidental pathological finding on a lymph node removed due to mammary cancer (Table 1). By the time these dogs were evaluated at the HVE, most of them $(24 / 27,88.9 \%)$ had evident peripheral nodal involvement with clinically measurable disease, weight loss documented in $22 \%$, and fever in $18.5 \%$. The prognostic impact of these clinical manifestations has not been studied in dogs and would require a large prospective study to determine if factors such as fever and weight loss bear prognostic significance, ${ }^{23}$ like they do in humans. 
Table 2. Common laboratory findings in 27 dogs with lymphoma.

The table shows the main abnormalities found in blood cell counts and serum biochemistry.

\begin{tabular}{|l|c|c|}
\hline \multicolumn{1}{|c|}{ Laboratory finding } & Number of patients and percentage \\
\hline \multicolumn{1}{|c|}{ Anemia } & Mild (Ht 30-36\%) & $12(44.4 \%)$ \\
\hline Moderate $(\mathrm{Ht}$ 20-29\%) & $2(7.4 \%)$ \\
\hline & Severe $(\mathrm{Ht}<19 \%)$ & $1(3.7 \%)$ \\
\hline Leukocytosis & $15(55.5 \%)$ \\
\hline Thrombocytopenia & $11(40.7 \%)$ \\
\hline Hypoalbuminemia & $4(14.8 \%)$ \\
\hline Elevated creatinine & $8(29.6 \%)$ \\
\hline Elevated alkanine phosphatase (ALP) & $3(11.11 \%)$ \\
\hline Elevated alanine aminotransferase (ALT) & $14(51.9 \%)$ \\
\hline Hyperbilirrubinemia & Conjugated & $5(18.5 \%)$ \\
\hline & Unconjugated & $1(3.7 \%)$ \\
\hline
\end{tabular}

As part of the diagnostic staging at pretreatment workup, the most common laboratory abnormality was normochromic normocytic anemia (55.5\%), mild in 12 patients (hematocrit: 30-36 \%), moderate in 2 (hematocrit: 20-29\%), and severe in 1 (hematocrit: 16\%). Eleven (40.7\%) had leukocytosis $\left(>17 \times 10^{9} / \mathrm{L}\right)$ at diagnosis, none presented a leucopenia, and four had moderate thrombocytopenia, $<200 \times 10^{9} / \mathrm{L}\left(108-180 \times 10^{9} / \mathrm{L}\right)$. Hypoalbuminemia was present in $29.6 \%$ of dogs $(<29 \mathrm{~g} / \mathrm{L})$, elevated creatinine $(>130 \mu \mathrm{mol} / \mathrm{L})$ in $11.11 \%$, alkaline phosphatase $(>189 \mathrm{U} / \mathrm{L})$ in $51.9 \%$, ALT ( $>70 \mathrm{U} / \mathrm{L})$ in 18.5\%, and hyperbilirubinemia in 29.6\% (one dog with high conjugated $(>4.3 \mu \mathrm{mol} / \mathrm{L}$ ), 5 with elevated unconjugated $(>2.6 \mu \mathrm{mol} / \mathrm{L})$ and 2 with mixed hyperbilirubinemia). There were no patients with hypercalcemia. LDH and beta-2 microglobulin levels were not routinely performed. Chest $X$ rays showed a mediastinal mass in 16\% (3/19) of patients. Of the 19 patients with abdominal ultrasound, one had lesions suggestive of hepatic infiltration, while splenic lesions suggestive of neoplastic infiltration were detected in 58\% (11/19); five with beehive appearance and 6 with multiple focal lesions (Table 2). According to WHO staging criteria (24), at initial diagnosis one patient (4\%) had early stage IA disease; seven (26\%) stage IIIb, and 19 patients (70.4\%) stage IV (Table 1). Bone marrow aspirates or biopsies were not routinely performed, thus stage $V$ (marrow infiltration) could not be evaluated. Most of the canine lymphoma patients (80\%) are diagnosed in advanced stages (III or IV) of 


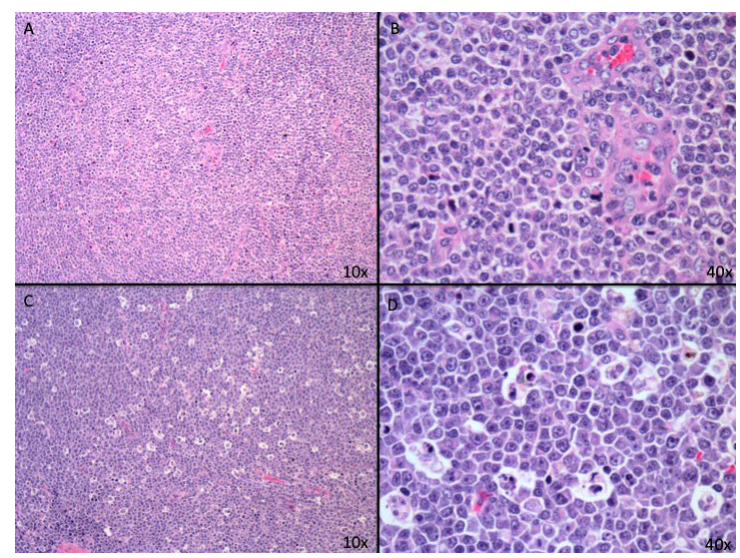

Figure 1. The only two histopathological patterns observed in canine lymphoma biopsies. Two morphological patterns were observed by hematoxylin and eosin staining. The first with diffuse susbstitution of the lymph node architecture by large cells resembling inmunoblasts and scarce centroblasts A (10x) and B (40x). The second with a similar diffuse nodal replacement by large centroblast-like cells with disperse immunoblasts and numerous tingible body marhophages giving a starry sky-like appearance C (10x) and D (40x).

disease according to the $\mathrm{WHO}$ criteria. 13,25 No standardized staging procedures are used in dogs, with around 75\% of veterinarians ordering basic laboratory and imaging work-up (CBC, biochemical profile, urinalysis, cytology of enlarged lymph node, thoracic radiographs and abdominal ultrasound), ${ }^{26}$ while bone marrow biopsies are rarely performed. The absence of routine bone marrow biopsies represents a limitation of the present study, given that marrow involvement is by definition stage V. Thus, some patients may have been understaged.

Pathological confirmation of lymphoma subtypes requires excisional tumor biopsy, in order to determine the pattern of infiltration and perform immunohistochemistry. Despite this, a fine needle aspirate (FNA) for cytology is still the most widely used technique. Immunophenotyping by flow cytometry could be done on a cytology sample, however, this technique is not available for dogs in Mexico. ${ }^{27}$ The initial diagnosis of lymphoma was made by cytology on FNA in all of our patients, while only 11 had an excisional biopsy for histopathology. On pathological review of tissue biopsies, there were only two histological patterns with all tumors showing diffuse nodal replacement by large cells. In one pattern, (6/11) there was a predominance of large cells resembling immunoblasts (amphophilic cytoplasm, eccentric nuclei, and one central nucleolus) with scattered centroblasts (round nuclei, dispersed chromatin, and basophilic cytoplasm). Of these six tumors, four were T-cell derived with positive CD3 membrane staining. In the second pattern (5/11), the large cells were predominantly centroblasts with scattered immunoblasts and additional numerous tingible-body-macrophages (Fig. 1), and none stained for T-cells (CD3). None of the T-cell derived lymphomas showed macrophage infiltration. CD79a staining with Dako, clone JCB 117 did not cross-react optimally with dog B-cells. Furthermore, available antibodies for immunohistochemistry in dogs are directed against a small number of antigens, making the study of lymphoma subtypes difficult. ${ }^{7}$ This should be easier in the near future, since B-cell lineage markers such as PAX5 have been shown to be useful in dogs, though it requires validation, $^{28}$ and canine-specific anti-CD20 antibodies are under development. ${ }^{29}$ 
Interestingly, as opposed to other reports in which diverse lymphoma subtypes are described, we did not see low grade, small, or medium sized-cell lymphomas. ${ }^{30-33}$ In the eleven cases with excisional biopsies, only two morphological patterns were observed on H\&E staining. Both patterns corresponded to diffuse large cell lymphomas. Though one pattern had evident tingible-body macrophages suggestive of a high proliferative rate and resembled a starry sky appearance, these tumors do not seem to correspond to Burkitt's lymphoma, based on the size and morphology of malignant lymphocytes. Three studies describe a Burkitt's-like morphology in 1.6-16.6\% of canine lymphomas. ${ }^{7,34,35}$ It is not clear whether these are equivalent to human Burkitt's, in which a c-myc balanced translocation from chromosome 8 to genes encoding for immunoglobulin heavy or light-chains is a sine qua non. In dogs, the c-myc gene is located on chromosome 13; a translocation between this region and known immunoglobulin genes has not been reported. ${ }^{36}$ Regarding cell of origin, studies vary with some reporting a higher incidence of B-cell lymphomas, while in others T-cell lymphomas predominate. 7,16,30,35,37 We confirmed a T-cell origin in four of eleven lymphomas, a similar finding to that seen in a previous Mexican study which found a T-cell phenotype in half their patients (48.4\%). ${ }^{16}$ A significant variation in the relative prevalence of B-cell and T-cell lymphomas in relation to breeds has also been reported. T-cell lymphomas are more prevalent in Boxer, Shih-Tzu, Welsh Corgi and Siberian Husky breeds, as opposed to a higher incidence of B-cell lymphomas in Doberman, Cocker Spaniel, Labrador Retriever, Rottweiler, Basset Hound and mongrels. ${ }^{20,35}$

Treatment was initiated 13 days (mean, 1-41) after pathologic confirmation of lymphoma. Currently, dogs do not receive lymphoma subtype-directed treatment, despite chemotherapy being used for canine lymphoma since 1967,22,38 with $\mathrm{CHOP}$ becoming standard treatment in most countries regardless of the cell or origin or lymphoma subtype. 1,10,34,37-39

Close to two thirds of our patients received $\mathrm{CHOP}$ as first line therapy with an OR of 73\% (CR:3/20\%; PR: 8/53\%) with progressive disease in 4/27\%, and a median overall survival of 219 days (4-586 days). Patients who achieved CR and PR had a meantime to progression of 171 and 105 days, respectively. These results are less encouraging than other reports of $80-90 \%$ CR rates and meansurvivals of 12-18 months. 2,12,40-42 This may be due in part to the advanced stage of disease at diagnosis. Only 60\% (9/15) of patients completed the 19-week protocol with half $(7 / 15)$ having frequent treatment delays due to neutropenia. The reasons for stopping treatment were progressive disease ${ }^{3}$ and partial response. ${ }^{2}$ However, as seen in our cohort, relapse and disease-related deaths are frequent. ${ }^{2,40}$ Of the patients that did not receive chemotherapy, seven patients were treated at diagnosis with prednisone only due to poor performance status. Of these, 1 had SD for less than one month, 4 PD and 2 were lost to follow up. All non-treated patients died in less than two weeks (Fig. 2).

This is similar to reports of non-treated patients who have short survivals of 4-6 weeks, probably due to more advanced disease. ${ }^{40,43} \mathrm{~A}$ patient with cutaneous lymphoma achieved PR with lomustine and prednisone and is still alive at a follow up of 452 days. 


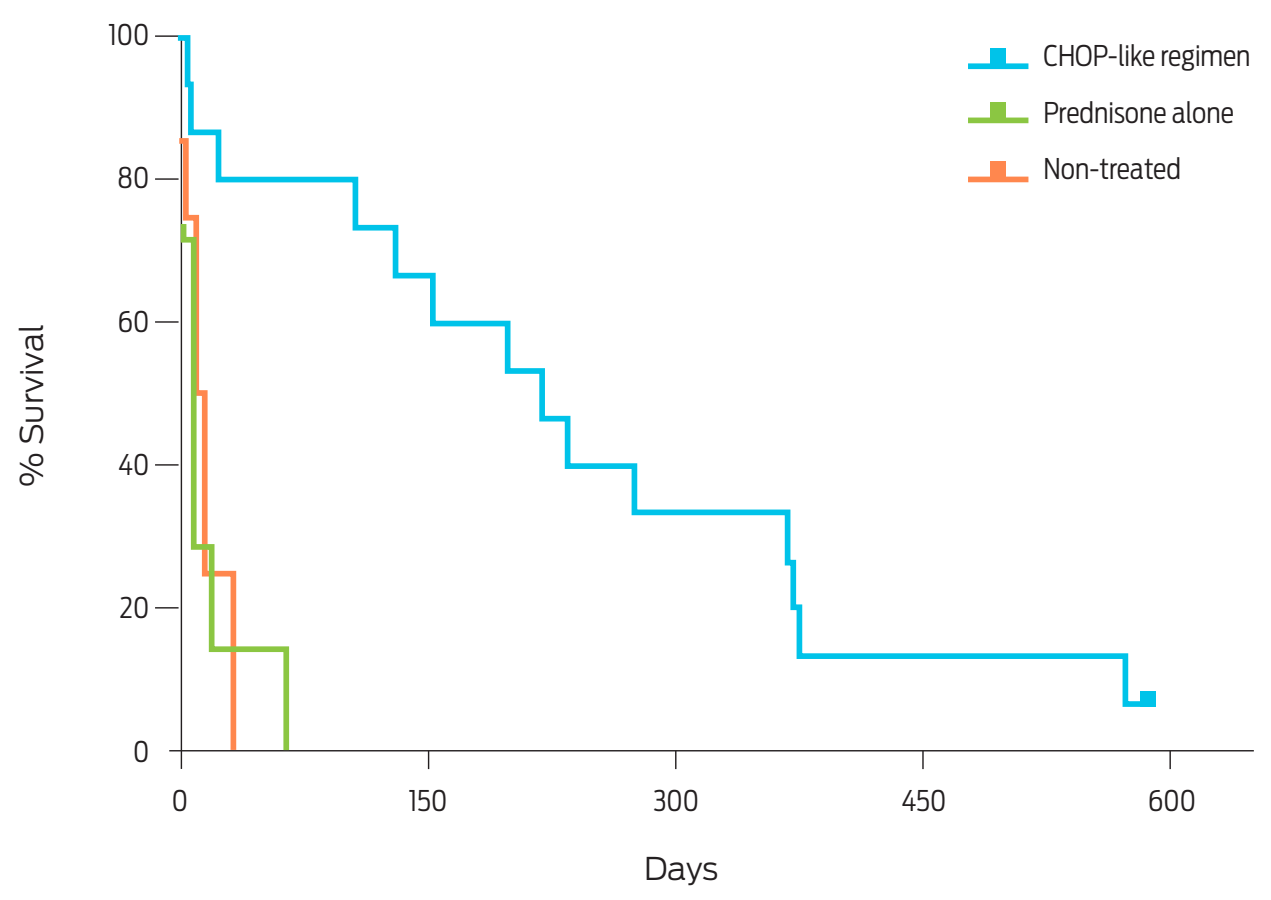

Figure 2. Overall survival of canine lymphoma patients by treatment regimen at diagnosis. Overall survival is shown for the two treatment regimens documented (CHOP-like and Prednisone) and for non-treated patients. The best outcome was seen in patients treated with the multi-drug scheme (blue continuous line). This may be because the multidrug chemotherapy was offered to the healthier and fitter dogs.

\section{Conclusions}

The demographic characteristics in this cohort are similar to studies reported in other countries. Although it was not possible to accurately establish bone marrow involvement, it is relevant that most patients (70\%) are seen in advanced stages of disease, at least in Stage IV. This highlights the need to implement programs to educate owners on the importance of an early detection. Interestingly, only highgrade tumors were found through histopathological review of lymph node biopsies. In order to achieve an accurate distinction between lymphoma subtypes excisional biopsies rather than fine needle aspirates should be carried out. A wider range of available antibodies for immunohistochemistry is much needed in dogs. This will lead to specific, more effective, and curative treatments. Pathological classification and disease-specific directed therapy in dogs lag far behind those achieved in humans. Worldwide collaborative studies between human and veterinary medicine are required. 


\section{Acknowledgements}

We thank our colleague Alejandra Zárate-Osorno M.D. for hemato-pathology review; Montserrat Segura and Nancy Abreu for their assistance in data recollection; and to the Federación Canófila Mexicana (FCM), LN and GCM for their financial support.

\section{Conflicts of interest}

There are no conflicts of interest to declare.

\section{Author contributions}

D.S. designed data collection, wrote the paper and analyzed data; R.S. performed and analyzed IHC; H.C. and A.G. collected and analyzed data; L.N. performed diagnosis and contributed materials and analytical tools; R.E.S. and L.A.M. analyzed data; G.C.M. designed data collection, contributed reagents and wrote the paper.

\section{References}

1. Ito D, Frantz AM, Modiano JF. Canine lymphoma as a comparative model for human non-Hodgkin lymphoma: recent progress and applications. Vet Immunol Immunopathol. 2014;159(3-4):192-201.

2. Vail D. Canine lymphoma and lymphoid leukemias. Feline lymphoma and leukemia. In: Withrow SJ, Vail DM, Page RL, editors. Withrow \& MacEwen's small animal clinical oncology. Saint Louis, Mo: Saunders; 2013. p. 608-50.

3. Boerkamp KM, Teske E, Boon LR, Grinwis GC, van den Bossche L, Rutteman GR. Estimated incidence rate and distribution of tumours in 4,653 cases of archival submissions derived from the Dutch golden retriever population. BMC Vet Res. 2014;10:34.

4. Zwingenberger AL, Kent MS, Shi C, Taylor SL, Chen X, Lam KS. Affinity of the alpha4-beta 1 integrin-targeting peptide LLP2A to canine lymphoma. Vet Immunol Immunopathol. 2012;145(1-2):298-304.

5. Dobson JM. Breed-predispositions to cancer in pedigree dogs. ISRN Vet Sci. 2013;2013:941275.

6. Theilen GH, Madewell BR, Gardner M B. Hematopoietic neoplasms, sarcomas and related conditions. Vet Cancer Med. 1987;2:392-407.

7. Ponce F, Marchal T, Magnol JP, Turinelli V, Ledieu D, Bonnefont C, et al. A morphological study of 608 cases of canine malignant lymphoma in France with a focus on comparative similarities between canine and human lymphoma morphology. Vet Pathol. 2010;47(3):414-33.

8. Teske E. Canine malignant lymphoma: a review and comparison with human non-Hodgkin's lymphoma. Vet Q. 1994;16(4):209-19.

9. Vail DM, Kisseberth WC, Obradovich JE, Moore FM, London CA, MacEwen EG, et al. Assessment of potential doubling time (Tpot), argyrophilic nucleolar organizer regions (AgNOR), and proliferating cell nuclear antigen (PCNA) as predictors of therapy response in canine non-Hodgkin's lymphoma. Exp Hematol. 1996;24(7):807-15.

10. Marconato L. The staging and treatment of multicentric high-grade lymphoma in dogs: a review of recent developments and future prospects. Vet J. 2011;188(1):34-8. 
11. Vail DM, Michels GM, Khanna C, Selting KA, London CA, Veterinary Cooperative Oncology G. Response evaluation criteria for peripheral nodal lymphoma in dogs (v1.0)-A Veterinary Cooperative Oncology Group (VCOG) consensus document. Vet Comp Oncol. 2010;8(1):28-37.

12. MacDonald VS, Thamm DH, Kurzman ID, Turek MM, Vail DM. Does L-asparaginase influence efficacy or toxicity when added to a standard CHOP protocol for dogs with lymphoma? J Vet Intern Med. 2005;19(5):732-6.

13. Devitt JJ, Maranon DG, Ehrhart EJ, Bachand AM, Lana SE, LaRue SM. Correlations between numerical chromosomal aberrations in the tumor and peripheral blood in canine lymphoma. Cytogenet Genome Res. 2009;124(1):12-8.

14. Dorn CR, Taylor DO, Hibbard HH. Epizootiologic characteristics of canine and feline leukemia and lymphoma. Am J Vet Res. 1967;28(125):993-1001.

15. Edwards DS, Henley WE, Harding EF, Dobson JM, Wood JL. Breed incidence of lymphoma in a UK population of insured dogs. Vet Comp Oncol. 2003;1(4):200-6.

16. Álvarez F. J. AG, Chávez G. Histological and immunophenotypic study of canine lymphoma in the center of Mexico. Vet Mexico. 2009;40:141-55.

17. Greenlee PG, Filippa DA, Quimby FW, Patnaik AK, Calvano SE, Matus RE, et al. Lymphomas in dogs. A morphologic, immunologic, and clinical study. Cancer. 1990;66(3):480-90.

18. Priester WA. Canine lymphoma: relative risk in the boxer breed. J Natl Cancer Inst. 1967;39(5):833-45.

19. Villamil JA, Henry CJ, Hahn AW, Bryan JN, Tyler JW, Caldwell CW. Hormonal and sex impact on the epidemiology of canine lymphoma. J Cancer Epidemiol. 2009;2009:591753.

20. Modiano JF, Breen M, Burnett RC, Parker HG, Inusah S, Thomas R, et al. Distinct B-cell and T-cell lymphoproliferative disease prevalence among dog breeds indicates heritable risk. Cancer Res. 2005;65(13):5654-61.

21. Priester WA, McKay FW. The occurrence of tumors in domestic animals. Natl Cancer Inst Monogr. 1980(54):1-210.

22. Núñez L. Linfosarcoma en perros. In: Muncha C. J. SCE, Pellegrino, editor. Consulta rápida en la clínica diaria. Buenos Aires: Intermédica; 2005. p. 649-52.

23. Howell DA, Warburton F, Ramirez AJ, Roman E, Smith AG, Forbes LJ. Risk factors and time to symptomatic presentation in leukaemia, lymphoma and myeloma. Br J Cancer. 2015;113(7):1114-20.

24. Owen LN, World Health Organization. TNM Classification of Tumours in Domestic Animal. Geneva: World Health Organization; 1980.

25. Schmidt JM, North SM, Freeman KP, Ramiro-lbanez F. Canine paediatric oncology: retrospective assessment of 9522 tumours in dogs up to 12 months (1993-2008). Vet Comp Oncol. 2010;8(4):283-92.

26. Regan RC, Kaplan MS, Bailey DB. Diagnostic evaluation and treatment recommendations for dogs with substage-a high-grade multicentric lymphoma: results of a survey of veterinarians. Vet Comp Oncol. 2013;11(4):287-95.

27. Aniołek O, Gajewski Z, Giziński S. Application of flow cytometry in diagnosing lymphomas in dogs and cats. Central-European journal of immunology. 2014;39(3):327-30.

28. Willmann M, Mullauer $L$, Guija de Arespacochaga A, Reifinger M, Mosberger I, Thalhammer JG. Pax5 immunostaining in paraffin-embedded sections of canine 
non-Hodgkin lymphoma: a novel canine pan pre-B- and B-cell marker. Veterinary immunology and immunopathology. 2009;128(4):359-65.

29. Jubala CM, Wojcieszyn JW, Valli VE, Getzy DM, Fosmire SP, Coffey D, et al. CD20 expression in normal canine $B$ cells and in canine non-Hodgkin lymphoma. Vet Pathol. 2005;42(4):468-76.

30. Guija de Arespacochaga A, Schwendenwein I, Weissenbock H. Retrospective study of 82 cases of canine lymphoma in Austria based on the working formulation and immunophenotyping. J Comp Pathol. 2007;136(2-3):186-92.

31. Sueiro FA, Alessi AC, Vassallo J. Canine lymphomas: a morphological and immunohistochemical study of 55 cases, with observations on p53 immunoexpression. J Comp Pathol. 2004;131(2-3):207-13.

32. Valli VE, San Myint M, Barthel A, Bienzle D, Caswell J, Colbatzky F, et al. Classification of canine malignant lymphomas according to the World Health Organization criteria. Vet Pathol. 2011;48(1):198-211.

33. Vezzali E, Parodi AL, Marcato PS, Bettini G. Histopathologic classification of 171 cases of canine and feline non-Hodgkin lymphoma according to the WHO. Vet Comp Oncol. 2010;8(1):38-49.

34. Flood-Knapik KE, Durham AC, Gregor TP, Sanchez MD, Durney ME, Sorenmo $\mathrm{KU}$. Clinical, histopathological and immunohistochemical characterization of canine indolent lymphoma. Vet Comp Oncol. 2013;11(4):272-86.

35. Lurie DM, Lucroy MD, Griffey SM, Simonson E, Madewell BR. T-cell-derived malignant lymphoma in the boxer breed. Vet Comp Oncol. 2004;2(3):171-5.

36. Pickering CR, Zhang J, Yoo SY, Bengtsson L, Moorthy S, Neskey DM, et al. Integrative genomic characterization of oral squamous cell carcinoma identifies frequent somatic drivers. Cancer Discovery. 2013;3(7):770-81.

37. Nelson RW, Couto CG. Small animal internal medicine. St. Louis, Mo: Mosby; 1998.

38. Squire RA, Bush M, Melby EC, Neeley LM, Yarbrough B. Clinical and pathologic study of canine lymphoma: clinical staging, cell classification, and therapy. J Natl Cancer Inst. 1973;51(2):565-74.

39. Keller ET, MacEwen EG, Rosenthal RC, Helfand SC, Fox LE. Evaluation of prognostic factors and sequential combination chemotherapy with doxorubicin for canine lymphoma. J Vet Intern Med. 1993;7(5):289-95.

40. Burton JH, Garrett-Mayer E, Thamm DH. Evaluation of a 15-week CHOP protocol for the treatment of canine multicentric lymphoma. Vet Comp Oncol. 2013;11(4):306-15.

41. Chun R, Garrett LD, Vail DM. Evaluation of a high-dose chemotherapy protocol with no maintenance therapy for dogs with lymphoma. J Vet Intern Med. 2000;14(2):120-4.

42. Garrett LD, Thamm DH, Chun R, Dudley R, Vail DM. Evaluation of a 6-month chemotherapy protocol with no maintenance therapy for dogs with lymphoma. J Vet Intern Med. 2002;16(6):704-9.

43. MacEwen EG, Patnaik AK, Wilkins RJ. Diagnosis and treatment of canine hematopoietic neoplasms. Vet Clin North Am. 1977;7(1):105-18. 